This item was submitted to Loughborough's Research Repository by the author.

Items in Figshare are protected by copyright, with all rights reserved, unless otherwise indicated.

\title{
Parental eating disorder symptoms and observations of mealtime interactions with children
}

PLEASE CITE THE PUBLISHED VERSION

http://dx.doi.org/10.1016/j.jpsychores.2010.07.006

PUBLISHER

(C) Elsevier

VERSION

AM (Accepted Manuscript)

LICENCE

CC BY-NC-ND 4.0

\section{REPOSITORY RECORD}

Blissett, Jacqueline, and Emma Haycraft. 2019. "Parental Eating Disorder Symptoms and Observations of Mealtime Interactions with Children”. figshare. https://hdl.handle.net/2134/11294. 
This item was submitted to Loughborough's Institutional Repository (https://dspace.lboro.ac.uk/) by the author and is made available under the following Creative Commons Licence conditions.

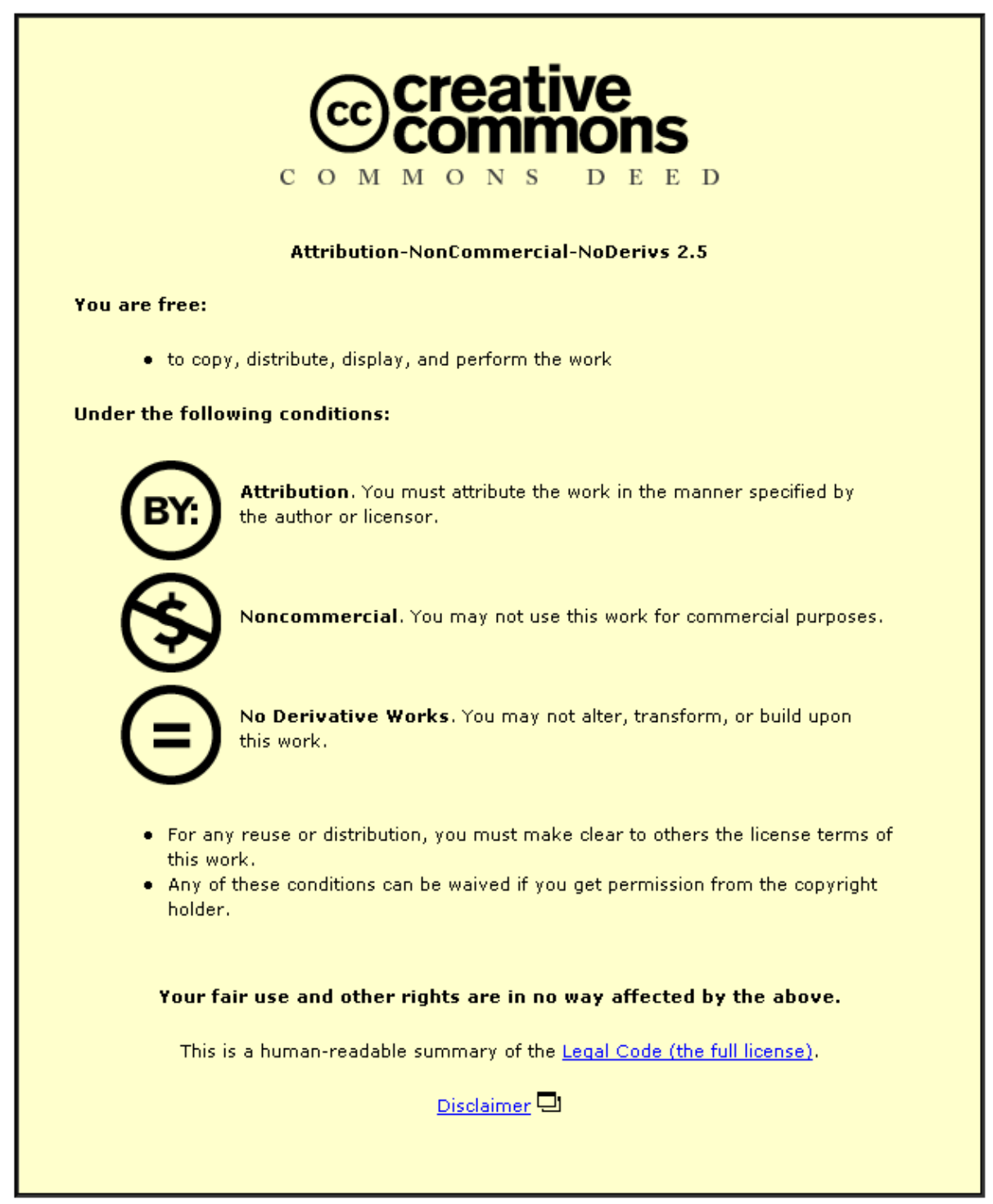

For the full text of this licence, please go to: http://creativecommons.org/licenses/by-nc-nd/2.5/ 
Short Report:

\section{PARENTAL EATING DISORDER SYMPTOMS AND OBSERVATIONS OF} MEALTIME INTERACTIONS WITH CHILDREN

Jackie Blissett ${ }^{\mathrm{a}}$, Ph.D. C.Psychol. \& Emma Haycraft ${ }^{\mathrm{b}}$, Ph.D.

${ }^{\text {a }}$ School of Psychology, University of Birmingham, Edgbaston, B15 2TT, UK.

${ }^{\mathrm{b}}$ School of Sport, Exercise and Health Sciences, Loughborough University, LE11 3TU, UK.

Please address all correspondence to Dr J Blissett email J.Blissett@bham.ac.uk. Not for publication: Tel 00441214143340 Fax 00441214144897

RUNNING HEAD: EATING PATHOLOGY AND OBSERVATIONS OF EATING Keywords: eating psychopathology; pressure to eat; restriction; child; mother; father 


\begin{abstract}
Objective: To examine relationships between parental eating disorder symptomology and observed feeding interactions with children. Method: Twenty-three mother-father pairs of children between 18 months and 5 years completed a self report measure of eating disorders and were observed during a family mealtime. Results: Parental reports of eating disorder symptoms were related to observations of greater pressurising by both parents, maternal restriction of children's food intake and use of incentives to eat, more mouthfuls of food eaten by the child and less food refusal. Discussion: Observed controlling feeding practices are related to symptoms of eating disorders in non-clinical groups of mothers and fathers, highlighting one mechanism by which eating distress may be transmitted within families.
\end{abstract}


Short Report:

\section{PARENTAL EATING DISORDER SYMPTOMS AND OBSERVATIONS OF MEALTIME INTERACTIONS WITH CHILDREN}

Parental use of controlling feeding practices, particularly restriction, have been shown to predict subsequent eating in the absence of hunger, disinhibited eating and weight increases in young children $(1,2)$. Parents' use of controlling feeding practices is predicted by a variety of factors including mental health (3). Mothers with both clinical and non-clinical symptoms of eating psychopathology are more intrusive and controlling of their children's mealtimes and report using more restrictive feeding practices $(4,5)$. Furthermore, women with anorexia nervosa perceive their infants to have more early onset feeding problems and the infants of women with bulimia nervosa are more likely to be overweight and grow more rapidly (6). Self report studies examining the role of the father in feeding interactions, suggest that fathers' eating psychopathology is related to paternal use of controlling feeding practices (4) and that fathers' eating attitudes and behaviours are important determinants of children's eating attitudes and behaviours (7). However, there are no observational studies of both mothers and fathers which consider the relationships between eating disorder symptoms and feeding interactions with young children.

This study aimed to examine whether eating disorder symptoms of mothers and fathers showed a relationship with observed feeding practices and children's observed eating behaviour. We hypothesised that parents with higher rates of reported eating psychopathology would be observed to use more controlling feeding practices at mealtimes. We predicted that parental drive for thinness would be related to less food acceptance and more food refusal from the children during the observed 
mealtime, whereas parental symptoms of bulimia would be related to lower rates of food refusal and greater food intake during the meal.

\section{METHOD}

Participants: Following informed consent, 46 cohabiting parents, (23 mothers, 23 fathers) participated. There were 23 children (14 girls, 9 boys), mean child age $=37$ months ( $\mathrm{SD}=13.96$, range 18-67). Families had an average of two children, ranging from 1-7. Where families had more than 1 child they were asked to report on the youngest child. Families were recruited through pre-school nurseries in the West Midlands and Cambridge, UK, as part of a larger study on family relationships and eating (8). In this larger study, approximately 1500 potential participants received information inviting them to take part in the study and $11.2 \%$ responded positively. Respondents were excluded if they were not cohabiting or if they failed to complete all of the questionnaire measures. This left a potential participant pool of 156 families. Participants for the sub-study involving a home visit were identified by selecting those families for whom both mother and father completed the questionnaire measures, and for ease of visiting by the researcher. Thus, fifty eight families in total were requested to engage in an observation of mealtimes.

Parents completed their responses separately. Data on ethnicity were not collected, but the nurseries served predominantly white, middle-class neighbourhoods. Parents were predominantly in 'managerial and professional occupations' (79\% of mothers, $84 \%$ of fathers) using the National Statistics Socio-Economic Classification (9). Mothers reported a mean of 5 years education post-16 $(\mathrm{SD}=2.70$, range $0-9)$; fathers reported similarly (mean=6.3, $\mathrm{SD}=4.49$, range $0-18)$.

$\underline{\text { Measures and procedure: }}$ 
Eating Disorder Inventory-2 (EDI-2; 10): The three eating symptom subscales of the EDI-2 were used: Drive for Thinness (e.g. 'I feel extremely guilty after overeating'); Bulimia (e.g. 'I have gone on eating binges where I have felt that I could not stop'); and Body Dissatisfaction (e.g. 'I think that my stomach is too big'). Parents respond using a six point scale (always-never). Higher scores indicate greater pathology. The EDI-2 displays good reliability, internal consistency, and validity (10). Mealtime observation: Families were observed during a typical mealtime at home. A camcorder (Panasonic NV-GS3B) was used to record the mealtime and the researcher left the room. Mealtime recordings were coded in real time using alloccurrence sampling, the Family Mealtime Coding System (FMCS) and Obswin 32 observational software (11). The reliability of parental report of feeding practices and differences between maternal and paternal feeding practices in this sample has been reported elsewhere and a detailed description of the FMCS coding system is described therein (12). The four FMCS subscales used in this study were: Parental verbal pressure for child to eat (observations of parents' verbal encouragements for child to eat more); Parental use of physical prompts for child to eat (e.g. observations of parents placing food on cutlery and pushing it towards child); Parental restriction of children's food intake (observations of parents verbally/physically limiting child's food intake); and Parental use of incentives (observations of parental use of bargaining/incentives as an attempt to increase child food intake). $13 \%$ of the recordings were coded by a trained, independent observer and inter-rater reliability was high (87-100\%). Two subscales of the Behavioural Coding Inventory (13) were used to code children's food acceptance and refusal behaviours. The number of mouthfuls of food consumed by the child was counted. Parents reported their height, 
weight and age. Children were weighed to the nearest $0.1 \mathrm{~kg}$ and measured to nearest $0.5 \mathrm{~cm}$. BMI SDS, adjusted for child age and gender, was recorded (14).

Parents were also asked to provide demographics and to detail the frequency with which they ate with their child in a typical week (of 3 meals and a snack per day; a total of 28 potential meals in one week).

Data analysis: Data were primarily non-normally distributed. Child gender, child age, parent BMI, SES, and years of post-16 education, were not related to children's eating behaviour and were not included in further analyses. Spearman's 1-tailed correlation coefficients were calculated to examine the relationship between parental reports of their eating psychopathology with observations of children's eating behaviour and parental feeding practices.

\section{RESULTS}

Descriptive statistics: The children's mean BMI SD score was 0.29 ( $\mathrm{SD}=1.12$, range 1.87 to 2.03). The mean age of the mothers was 36 years ( $\mathrm{SD}=4.39$, range 29-46) and fathers' mean age was 37 years $(\mathrm{SD}=4.54$, range $31-49)$. Mothers' mean $\mathrm{BMI}$ was $24.8(\mathrm{SD}=5.37$, range 19-40) and fathers' mean BMI was $26(\mathrm{SD}=2.99$, range 20-32). On average, mothers showed higher levels of eating psychopathology than did fathers: Drive for Thinness: maternal mean $=3.35(\mathrm{SD}=5.53)$, paternal mean $=1.00(\mathrm{SD}=$ 1.51). Bulimia symptoms: maternal mean $=1.35(\mathrm{SD}=2.48)$, paternal mean $=0.39$ $(\mathrm{SD}=.84)$. Body Dissatisfaction: maternal mean $=10.96(\mathrm{SD}=9.20)$, paternal mean $=$ $5.09(\mathrm{SD}=4.68)$. However, maternal scores are very similar to those reported in other studies of UK mothers and fathers of preschool children in the UK (4). Two mothers and no fathers had EDI scores that indicated potential clinical caseness (indicated by a cut off of above 14 on drive for thinness [15]). Mothers' and fathers' scores on drive for thinness and bulimia were not significantly correlated $(\mathrm{r}=-.11, \mathrm{p}=.31 ; \mathrm{r}=-.04$, 
$\mathrm{p}=.44$, respectively). However, maternal and paternal body dissatisfaction scores were positively correlated $(\mathrm{r}=.441, \mathrm{p}=.018)$. There were no significant differences in the observed feeding practices used by mothers and father during the mealtime. Details of these analyses can be seen elsewhere (12). Mothers rated themselves as eating more frequently with their children than did fathers (mothers mean $=19$ meals/snacks per week, $\mathrm{SD}=5.2$; fathers mean $=13$ meals/snacks per week, $\mathrm{SD}=3.8$ ). However although mothers did eat more frequently with their children than did fathers, this sample of fathers ate with their children approximately twice daily, suggesting that the recorded mealtime was not particularly unusual.

--- Table I about here ---

Table I demonstrates that there were no significant relationships between children's acceptance or rejection of food with maternal eating psychopathology, except that mothers who reported higher levels of bulimia had children who consumed a greater number of mouthfuls per mealtime. Fathers who reported higher bulimia scores had children who showed lower rates of food refusal. There were no other relationships between child eating behaviours and parental report of eating psychopathology. Mothers who had higher levels of eating pathology symptoms and fathers with higher levels of body dissatisfaction used more verbal pressure to eat. Mothers also used more physical prompts to eat when they had high levels of drive for thinness. Mothers with greater body dissatisfaction used more restrictive practices. Mothers also used greater restriction and use of incentives when the fathers reported higher levels of eating pathology.

\section{DISCUSSION}

This study observed some significant relationships between parents' eating psychopathology symptoms and observable mealtime eating behaviours and feeding 
practices in a non-clinical group. Restrictive feeding practices were used more frequently by mothers with higher levels of body dissatisfaction and in the context of higher levels of paternal symptoms of bulimia. Observed restriction within mealtimes is relatively unusual (16) and this association suggests that these mothers may be concerned about their children's eating or likelihood of weight gain. Relationships were established between maternal practices and paternal eating disorder symptoms suggesting that paternal eating pathology may be an important predictor of children's eating experiences partly because of its relationship with maternal feeding practices.

Parental symptoms of body dissatisfaction were associated with greater use of pressurising feeding practices. Mothers also used more incentives to eat when paternal body dissatisfaction was high. The use of pressure to eat and incentives undermines the intrinsic value of eating, reduces children's consumption and enjoyment of pressured foods and increases preference for withheld or reward foods (1). Therefore, parents with symptoms of eating disorder may further disrupt their children's internal regulatory systems for the initiation and cessation of eating, and exaggerate innate food preferences for palatable foods. It is also important to note that maternal body dissatisfaction was related to the use of both pressure to eat and restriction. Parental use of both elements of controlling feeding practice may reflect a more controlling feeding style overall in which the parent attempts to reduce the child's consumption of 'less healthy' foods as well as to increase the child's consumption of 'healthy' foods. Mothers with greater body dissatisfaction may be particularly likely to use both of these forms of dietary control with their children, even though they have been shown to be counter-productive in terms of food intake and weight regulation (1).

Parental eating disorder symptoms may be reflected not only in the feeding practices that parents use but also in the eating behaviour of the children themselves, 
including consuming a greater number of mouthfuls, and lower rates of food refusal. Thus, the children of these parents may receive a genetic susceptibility to disorder or eating style and an eating environment which may distort self regulation of food intake.

There was no significant relationship between parental drive for thinness and objective measures of child food refusal or acceptance. However, mothers with higher drive for thinness used more physical prompts and verbal pressure to eat with their children. This suggests that, even in the absence of significant observable food refusal behaviours within the children, mothers with more symptoms of anorexia perceive that their children require encouragement to eat. It is therefore possible that maternal perceptions of reticence to eat are not always accurate in women with symptoms of anorexia.

There are several limitations to this study. This study was unable to answer questions about clinical eating pathology because only two of the mothers reported EDI scores that indicated potential caseness. Neither are we able to answer, with this small number of families, whether there are differences between families where both parents show symptoms of eating disorders compared to families where only one parent demonstrates such pathology. In this study, neither maternal drive for thinness nor bulimia were significantly correlated with paternal scores on these measures. However, parental body dissatisfaction was correlated within families. It may be useful to focus further work on the relative effects of consistency or divergence of parental eating attitudes on feeding practices within families.

Other limitations include the fact that the families that participated may not be representative of typical families; the parents in this study were well educated, limiting extrapolation of findings to less well educated samples. Parental age might be 
perceived as relatively high, perhaps because we were asking parents to report of their youngest child. However, the age of these parents is similar to other studies that we have carried out in the UK (4). Furthermore, the study focussed on just one child within a family. We were not able to look at the potential moderating effects of sibling presence or absence, nor on the potential effects of parental control of other siblings' eating on the target child's eating. The single observations of mealtimes may not have been representative and we have previously suggested that behaviour of mothers at mealtimes where the father is present may not be representative of her behaviour at other mealtimes (12). Furthermore, this study is cross sectional, preventing conclusions concerning causal relationships. However, this study suggests that there are clear relationships between parental symptoms of eating disorder and controlling, maladaptive feeding practices in non-clinical groups. Early over-control of children's food intake and eating behaviour may be one mechanism by which intergenerational transmission of eating disorder symptoms occurs. 


\section{References}

1. Birch LL, Fisher JO. Development of Eating Behaviors Among Children and Adolescents. Pediatrics 1998; 101: 539-549.

2. Faith MS, Scanlon KS, Birch LL, Francis LA, Sherry B. Parent-child feeding strategies and their relationships to child eating and weight status. Obes Res 2004; 12 : 1711-1722.

3. Blissett J, Farrow C. Predictors of maternal control of feeding at 1 and 2 years of age. Int J Obes 2007; 31: 1520-1526.

4. Blissett J, Meyer C, Haycraft E. Maternal and paternal controlling feeding practices with male and female children. Appetite 2006; 47: 212-219.

5. Stein A, Woolley H, McPherson K. Conflict between mothers with eating disorders and their infants during mealtimes. Br J Psychiatry 1999;175:455-61.

6. Micali N, Simonoff E, Treasure J. Infant feeding and weight in the first year of life in babies of women with eating disorders. J Pediat 2009; 154(1): 55-60.

7. Thelen MH, Cormier JF. Desire to be thinner and weight control among children and their parents. Behav Ther 1995;26(1):85-99.

8. Haycraft, E. \& Blissett, J. The role of parents' romantic relationship warmth and hostility in child feeding practices and children's eating behaviours. Mat Child Nutr, in press. DOI 10.1111/j.1740-8709.2009.00212.9. Office for National Statistics. The National Statistics Socio-Economic Classification.

(http://www.statistics.gov.uk/methods_quality/ns_sec); 2005.

10. Garner DM. Eating Disorders Inventory 2: Professional manual. Odessa, FL: Psychological Assessment Resources; 1991.

11. Martin NT, Oliver C, Hall S. Obswin 32: Observational data collection and analysis for Windows (Version 3) [Computer software]. School of Psychology, University of Birmingham; 2000.

12. Haycraft E, Blissett J. Maternal and paternal controlling feeding practices: Reliability and relationships with BMI. Obesity (Silver Spring) 2008; 16, 1552-1558. 13. Young B, Drewett R. Eating behaviour and its variability in 1-year-old children. Appetite 2000;35:171-7.14. Child Growth Foundation. Cross Sectional Stature and Weight Reference Curves for the UK. London, United Kingdom: Child Growth Foundation, 1996. 
15. McGrane, D, Carr, A. Young women at risk for eating disorders: Perceived family dysfunction and parental psychological problems. Contemporary Family Therapy, $2002 ; 24,385-395$.

16. Orrell-Valente JK, Hill LG, Brechwald WA, Dodge KA, Pettit GS, Bates JE. "Just three more bites": An observational analysis of parents' socialization of children's eating at mealtime. Appetite 2007; 48:37-45. 